Syntax Idea: p-ISSN: 2684-6853 e-ISSN: 2684-883X

Vol. 3, No. 2, Februari 2021

\title{
KRISIS KETELADANAN KEPEMIMPINAN GEREJA: FONDASI GEMBALA SEBAGAI PEMIMPIN GEREJA BERDASARKAN 1 PETRUS 5:2-4
}

\section{Djone Georges Nicolas dan Tirza Manaroinsong}

Sekolah Tinggi Theologi IKAT (STTI) Jakarta dan Sekolah Tinggi Theologi (STT)

Permata Bangsa Barito Jakarta, Indonesia

Email: djonealexandrenathanael@gmail.com dan irzapoppy.manaroinsong@gmail.com

\section{Abstract}

The purpose of this study was to analyze the crisis of the accuracy of church leadership: the foundation of the shepherd as the leader of the church based on 1 peter 5: 2-4. This research uses descriptive qualitative methods and literature analysis, with the aim of analyzing the crisis of exemplary church leadership and the role of pastors as church leaders based on 1 Peter 5:2-4. Data collection through Bible sources, books, journals, digital articles, and other documents related to the issues studied. Qualitative research according to Bodgan and Biklen. The result of his research is: First, the shepherd as the leader of the church needs to realize that his leadership is the trust and trust of the Lord. Second, the shepherd's leadership qualities must be superior to leadership in general by providing adence through volunteerism and self-devotion in serving the church he leads. Third, there is an eternal appreciation for the shepherd who leads by setting an example.

Keywords: crisis, example; leadership; church; shepherd's foundation; peter 5: 2-4

\begin{abstract}
Abstrak
Tujuan penelitian ini adalah untuk mengalisis krisis keteladanan kepemimpinan gereja: fondasi gembala sebagai pemimpin gereja berdasarkan 1 petrus 5: 2-4. Penelitian ini menggunakan metode kualitatif deskriptif dan analisa literatur, dengan tujuan menganalisa krisis teladanan kepemimpinan gereja dan peran gembala sebagai pemimpin gereja berdasarkan 1 Petrus 5:2-4. Pengumpulan data melalui sumber Alkitab, buku-buku, jurnal-jurnal, artikel digital, dan dokumen lain yang berkaitan dengan masalah yang dikaji. Penelitian kualitatif menurut Bodgan dan Biklen. Hasil penelitiannya adalah: Pertama, gembala sebagai pemimpin gereja perlu menyadari bahwa kepemimpinan-nya merupakan kepercayaan dan amanah dari Tuhan. Kedua, kualitas kepemimpinan gembala harus unggul dari kepemimpinan pada umumnya dengan memberi keteladanan melalui kesukarelaan dan pengabdian diri dalam melayani jemaat yang dipimpinnya. Ketiga, terdapat penghargaan yang bersifat kekal bagi gembala yang memimpin dengan memberi teladan.
\end{abstract}

Kata kunci: krisis; keteladanan; kepemimpinan; gereja; fondasi gembala; petrus 5:2-4 


\section{Pendahuluan}

Kemajuan teknologi ini membuat banyak perusahaan menggunakan teknologi berbasis komputer dan jaringan untuk membantu pekerjaanya karena bersifat efektif dan efisien (Nurkarsa, 2019).

Pada era globalisasi abad 21 dimana perubahan menjadi tantangan tersendiri dan tidak terbendung, dimana kualitas menjadi tuntutan utama, kepemimpinan menjadi topik yang paling hampir sering dibahas dan bahkan diajarkan, baik melalui seminarseminar, konferensi-konferensi berskala internasional maupun nasional, mengingat bahwa kepemimpinan merupakan titik sentral dalam model organisasi apapun, dan kepemimpinan sangat menentukan arah berjalannya suatu organisasi dan hasil yang akan dicapainya. Namun, arah kepemimpinan mulai kehilangan maknanya, sebab kepemimpinan mulai digunakan sebagai "prestige" sang pemimpin dan sarana untuk meraih keuntungan pribadi, sehingga kepemimpinan bukan lagi dipandang sebagai kepercayaan dan amanah. Itu merupakan sesuatu yang memprihatinkan atau dengan kata lain sebuah krisis. Krisis di artikan menurut Kamus Besar Bahasa Indonesia (KBBI) sebagai keadaan yang suram dan genting, menghawatirkan maupun membahayakan (Catur Hari Wibowo, 2015).

Kepemimpinan dipandang sangat penting karena dua hal: pertama, adanya kenyataan bahwa penggantian pemimpin seringkali mengubah kinerja suatu unit, instansi atau organisasi; kedua, hasil penelitian yang menunjukkan bahwa salah satu faktor internal yang mempengaruhi keberhasilan organisasi adalah kepemimpinan, mencakup proses kepemimpinan pada setiap jenjang organisasi, kompetensi dan tindakan pemimpin yang bersangkutan (Udik Budi Wibowo, 2011).

Kepemimpinan merupakan hal yang sangat dasar dan prinsipil dalam semua organisasi termasuk di dalam gereja. Bicara kepemimpinan tentunya juga berbicara tentang siapa yang memimpin dan juga bagaimana dia memimpin, sebab sehat atau sakit maupun sukses dan gagal sebuah organisasi ditentukan oleh pemimpinnya. Memimpin bagi John Stott diartikan sebagai berjalan di depan, menunjuk jalan serta memberi inspirasi kepada orang lain supaya mereka mengikutinya (Razak, Mokhtar, \& Sulaiman, 2018).

Kepemimpinan dalam organisasi memiliki peran yang sangat besar dalam membangun hubungan antar individu dan pembentuk nilai organisasi yang dijadikan sebagai pondasi dasar bagi pencapaian tujuan organisasi. Pengaruh kepemimpinan terhadap efektivitas organisasi dapat dilihat sebagai efek kepemimpinan langsung dan tidak langsung (Baharun, 2018).

Di dalam gereja sebagai organisasi, gembala sidang merupakan pemimpinnya. Gembala merupakan faktor yang sentral dan menentukan proses pertumbuhan gereja yang dipimpinya agar tetap sehat. Gembala yang kepemimpinan-nya berkualitas, akan menghasilkan pelayanan yang bermutu dan produktif sehingga dapat memenuhi kebutuhan jemaat sebagai domba-domba yang telah dipercayakan Allah untuk dipelihara. (Dewi, 2019) menyatakan bahwa kepemimpinan gembala tidaklah sebatas sebuah jabatan sebagai status, tetapi kepemimpinan gembala adalah keteladanan melalui karakternya, sebab keteladanan dan kepemimpinan tidak terpisahkan. Sependapat, bagi 
(Samarenna \& Siahaan, 2019) kepemimpinan merupakan cara pemimpin dapat memberi teladan melalui tindakan kasih. Menurut (Purwanto, 2020), gembala dalam kepemimpinannya adalah pemimpin yang melayani dan menjadi orangtua rohani bagi jemaat.

Di sisi lain melalui wawancara, Evangelist Etougou Marc Orland berkata: "Jujur, hari-hari ini sukar menemukan gembala yang memberi teladan, sebab gembala sudah bedah tipis dengan artis, pakai mobil Alfart dan pamer postingan makan di restoran mahal sedangkan jemaatnya kelaparan dan hidup susah. Lebih baik Jokowi yang bukan orang kristen tetapi jelas sebagai pemimpin memberi contoh bagi rakyat dengan menjadi orang pertama yang divaksin antivirus Covid-19 tanpa menghiraukan resiko nyawanya".

Gembala sebagai pemimpin bertanggungjawab membina, merawat, menuntun, menjaga, memberi teladan dan memastikan pertumbuhan jemaat hingga mewujudkan pertumbuhan hingga kedewasaan rohani mereka sesuai kehendak Tuhan. Namun pada kenyataannya, ditemukan gembala yang justru menjadi batu sandungan dan mencelakakan jemaat yang seharusnya dirawat dan dijaga sebaik-baiknya dengan kasih. Kekecewaan jemaat terhadap kepemimpinan gembala sidang menurut Dapo Tua Simanjuntak merupakan salah satu penyebab terjadi kemunduran dan perpecahan di dalam tubuh gereja (Liliaprianty, 2020).

Pada Rabu 4 Maret 2020 dalam Tribunnews.com, di surabaya terungkap laporkan ke pihak berwajib dengan surat laporan bernomor LPB/155/II/2020/UM/SPKT, kasus seorang pendeta dan gembala jemaat yang bernama dengan inisial HL yang telah melakukan pelecehan seksual terhadap jemaatnya sendiri yang bernama berinisial IW selama tujuh belas tahun, yakni sejak korban berusia sembilan tahun hingga dua puluh enam tahun sehingga mengakibatkan korban mengalami depresi tinggi. Dan ironisnya, perbuatan tidak bermoral tersebut selalu dilakukan di gedung gereja. Di sisi lain melalui detiknews bertanggal 12 Maret 2020, gaya kehidupan mewahnya sang pendeta sebagai hamba Tuhan menjadi sorotan warga media sosial oleh karena barang yang digunakannya: seperti koleksi jam tangan seharga 205,598 USD atau sekitar 3 Miliar Rupiah bermerek Audemars Piguet Royal Offshoure, Rolex Submariner dengan nilai 12,500 USD atau hamper 175 juta Rupiah, Rolex tipe lain bernilai 13,688 USD atau sebanding dengan harga 190 juta Rupiah, jam senilai 14,498 USD atau setara dengan 200 juta Rupiah bermerek deLaCour diikuti beberapa komen akun yang mengucapkan kecewa karena gaya hidup glamour sang pendeta sehingga dijuluki "sang serigala berbulu domba".

Menurut (Benjamin \& Biswas, 2019) menyatakan bahwa sebutan gembala dapat disamakan dengan kepemimpinan yang eksemplaris atau kepemimpinan yang memberi contoh. Jika gembala yang seharusnya menjadi berkat bagi jemaatnya dengan memimpin mereka kepada rumput yang hijau dan air yang tenang melalui keteladannya agar pertumbuhan mereka terjadi, dan dengan demikian pertumbuhan gereja juga semakin nyata justru merugikan dan mengecewakan mereka, apa yang dapat diharapkan dari gereja? Apa yang mau dicontoh dari seorang pemimpin rohani yang tidak dapat dipercayai? Apa yang menjadi dasar dan peran kepemimpinan seorang gembala jemaat? 
Tanggungjawab kepemimpinan gereja bukanlah tugas yang ringan oleh karena di dalamnya dibutuhkan pengorbanan yang tidak sedikit, sehingga diperlukan kerelaan hati dan pengabdian diri yang total sang gembala dalam melaksanakan tugas seperti yang tercantum di dalam Surat 1 Petrus 5:2-4.

\section{Metode Penelitian}

Penelitian ini menggunakan metode kualitatif deskriptif dan analisa literatur, dengan tujuan menganalisa krisis keteladanan kepemimpinan gereja dan peran gembala sebagai pemimpin gereja berdasarkan 1 Petrus 5:2-4. Pengumpulan data melalui sumber Alkitab, buku-buku, jurnal-jurnal, artikel digital, dan dokumen lain yang berkaitan dengan masalah yang dikaji. Penelitian kualitatif menurut Bodgan dan Biklen (Anggito \& Setiawan, 2018) adalah suatu prosedur penelitian yang menghasilkan tipe data deskriptif berupa ucapan atau tulisan maupun perilaku orang-orang yang diamati di dalam suatu konteks dan dikaji dari sudut pandang yang lengkap dan komprehensif, maupun menyeluruh atau holistik

\section{Hasil dan Pembahasan}

1. Krisis Keteladanan Kepemimpinan Gereja

Krisis keteladan kepemimpinan di dalam gereja nyata di era global ini dan tentunya jadi ancaman bagi gereja, khususnya bagi jemaat yang sangat membutuhkan keteladanan gembala sebagai pemimpin mereka. Menurut (Tambunan, Sihombing, Doloksaribu, \& Muda, 2018), keprihatinan terjadi dalam lembaga-bembaga Kristen yang tidak berlaku berbeda dengan model dunia dimana terjadi KKN dalam pemilihan-pemilihan pimpinan sinode gereja, dan juga korupsi yang dilakukan oleh pemimpin. Ibu Yanti Kabid Ibadah Gereja Bethel Indonesia CK5 Filadefia Jelambar mengutarakan kekecewaannya melalui wawancara dengan berkata: "Sudah mau satu tahun sejak mulai pandemi Covid-19 tidak pernah ada ibadah walaupun secara online, justru gembala lepas tanggungjawab dan suruh kita jemaat ikuti ibadahibadah yang sudah ada di Youtube gereja lain. Tidak ada bimbingan rohani sama sekali seolah gereja sudah tutup".

Ditemukan juga gembala sebagai pemimpin yang membiarkan domba-domba kelaparan dan fokus mencari makanan bagi dirinya, menjaga dirinya lebih dari pada menjaga domba-domba Allah (Hakh, 2019).

Keteledanan merupakan bagian yang melekat pada kepemimpinan secara umum dan secara khusus dalam kepemimpinan gembala di dalam gereja. Sebab, apabila kepemimpinan dunia saja menuntut keteladanan dari seorang pemimpin, terlebih dunia rohani yang mengutamakan karakter sebagai buah yang dapat dinikmati oleh orang yang dipimpin seorang gembala. Sama seperti Gembala Agung Yesus Kristus telah memberi teladan selama hidup dan melayani di bumi ini, para gembala mempunyai tanggungjawab memberi contoh Sang Guru Agung dengan memberi teladan bagi jemaat Tuhan, bahkan bagi dunia ini sehingga hakekat terang dan garam menjadi nyata dan bukan sekedar slogan. Fondasi Gembala sebagai Pemimpin Gereja berdasarkan 1 Petrus 5:2-4 
a. Gembala sebagai pemimpin gereja perlu menyadari bahwa kepemimpinan-nya merupakan kepercayaan dan amanah dari Tuhan Menjadi gembala atau leader bagi jemaat yang merupakan domba-domba Allah merupakan panggilan khusus dari Allah sendiri dan bukan inisiatif siapapun. 1 Petrus 5:2-3 menegaskan tiga hal: pertama, "Gembalakanlah kawanan domba Allah yang ada padamu..." (ayat 2), kata "gembalakan" kawanan domba Allah merupakan satu perintah yang harus dilaksanakan dengan sebaik mungkin. (Rupa, 2016) menyatakan bahwa kata gembalakankalah bukan sekedar perintah biasa, tetapi perintah untuk melayani. Kedua, bahwa jemaat yang digembalakan atau dipimpin oleh seorang gembala merupakan domba-domba Allah. Istilah 'kawanan domba” dimaknai " $a$ group of Christ's disciples" (Sekelompok murid Kristus) dan juga "Bodie of Christian (churches) presided over by elders" (Tubuh Kristus (Gereja) yang dipimpin oleh para penatua). Dengan kata lain, kawanan domba Allah identik dengan jemaat Tuhan dan bukan milik gembala yang memimpin mereka sementara di dunia. Maka, konkordansi menurut Shellabear menulis "Bimbinglah jemaah umat Allah yang ada di bawah tanggung jawabmu..." (alkitab.sabda.org). Itu sama dengan ketika Yesus memberi perintah kepada Petrus untuk menggembalakan, Dia menekankan kepada Petrus bahwa dombadomba tersebut bukanlah milik petrus, tetapi milik-Nya sendiri yang dititipkan untuk dituntun. Maka dia pakai istilah "gembalakanlah domba-dombaKu" (Yohanes 21:15-17). Ketiga, memimpin atau menggembalakan jemaat Tuhan merupakan suatu kepercayaan dan amanah yang berasal dari Tuhan. Oleh karena pada dasarnya domba-domba merupakan milik Tuhan, secara logis manusia sebagai gembala hanya melaksanakan amanah yang telah dipercayakan oleh Tuhan. 1 Petrus 5:3 memberi penegasan tersebut dengan berbunyi "Janganlah kamu berbuat seolah-olah kamu mau memerintah atas mereka yang dipercayakan kepadamu...”. Kata dipercayakan dimaknai sebagai diberi sebuah tanggungjawab oleh Allah sehingga pasti akan dituntut pertanggungjawaban oleh Allah. Maka (AYT, 2018) menuliskan "Jangan pula bertindak sebagai penguasa terhadap mereka yang dipercayakan ke dalam tanggung jawabmu...". (Sitepu, 2019) menyampaikan bahwa kepemimpinan gereja tidak bisa dipisahkan dari cara menangani tugas yang Tuhan percayakan.

b. kualitas kepemimpinan gembala harus unggul dari kepemimpinan pada umumnya dengan memberi keteladanan melalui kesukarelaan dan pengabdian diri dalam melayani jemaat yang dipimpinnya Sebagai gembala yang telah diberi kehormatan dan dipercayakan melayani jemaat Tuhan, pelayanannya harus berkualitas dan unggul oleh karena kualitasnya yang tinggi dan terbaik, tetapi juga karena melalui kualitas tersebut pelayanan yang diberi bisa menjadi teladan bagi mereka yang dilayani dan dibimbing. Pelayanan yang berkualitas adalah pelayanan yang berkorban. Kalau Jokowi widodo sebagai presiden, Panglima TNI Jendral Hadi Tjahjanto, Kapolri Jendral Idham Azis, termasuk beberapa tokoh agama rela mengambil resiko demi memberi kepercayaan kepada rakyat untuk ikut divaksin antivirus Covid-19, memberi diri divaksin sebagai orang- 
orang pertama dengan segala kemungkinan resiko yang bisa timbul, bukankah seorang gembala sebagai pemimpin jemaat harus lebih dari pada itu mencontohi Yesus yang rela mati disalib demi menebus umat-Nya?

2. Keteladanan melalui kesukarelaan

Petrus 5:2 menyebutkan "Gembalakanlah kawanan domba Allah yang ada padamu, jangan dengan paksa, tetapi dengan sukarela sesuai dengan kehendak Allah...”. Kerelaan diartikan menurut Kamus Besar Indonesia (KBBI) sebagai keikhlasan hati, kesenangan hati, perkenan. Menggembalakan jemaat dengan kerelaan dimaksudkan melayani mereka dengan sepenuh hati oleh karena dasar kepercayaan dari Tuhan sehingga unsur paksaan tidak diperkenankan, sebab bagaimana pun gembala jemaat merupakan hamba Tuhan sehingga wajib taat kepadaNya. Dan Kesukarelaan gembala dalam memimpin jemaat harus dilandasi pada kehendak Allah dan bukan kehendaknya sendiri, sebab pelayananya adalah bagi Allah dan bukan bagi siapapun yang lain termasuk dirinya. Maka, Kolose 3:23 dengan tegas menyampaikan bahwa apapun yang dilakukan harus dilakukan hanya karena Tuhan dan untuk Tuhan, dan bukan untuk manusia. Atinya kerelaan berhubungan erat dengan motivasi seorang gembala dalam melayani atau memimpin umat Tuhan. Maka 1 Petrus 5:2 menambahkan bahwa motivasinya tidak boleh untuk mencari keuntungan pribadi, tetapi keuntungan bagi Kerajaan Allah.

3. Keteladanan Melalui Pengabdian Diri

“... dan jangan karena mau mencari keuntungan, tetapi dengan pengabdian diri" (1 Petrus 5:2). Kata mengabdi dari akar kata "abdi” yang didefinisikan sebagai budak tebusan, orang bawahan, hamba dan pelayanan. Mengabdi bagi seorang gembala jemaat merupakan sifat kerendahan hati yang bersumber dari kesadaran bahwa panggilannya adalah untuk melayani dan bukan memerintah, menjadi hamba dan bukan boss, wajib menjadi berkat dan bukan tuntut diberkati, berkorban dan bukan ingin meninggikan diri. Maka, 1 Petrus 5:3 memberi pengingat dengan berkata "Janganlah kamu berbuat seolah-olah kamu mau memerintah atas mereka yang dipercayakan kepadamu, tetapi hendaklah kamu menjadi teladan bagi kawanan domba itu." untuk menegaskan penting pengabdian diri dalam melayani sebagai gembala untuk memenuhi kebutuhan jemaat. (Rupa, 2016) menyatakan bahwa pengabdian diri tidaklah mudah, oleh karena pada umumnya semua orang ingin dilayani dan bukan melayani, namun itu terbalik bagi seorang gembala jemaat.

Pengabdian diri merupakan bukti konkret pengorbanan dan kasih seorang gembala bagi jemaat yang dipimpinnya dan sekaligus teladan bagi mereka yang digembalakan, seperti pengabdian Tuhan Yesus Kristus bagi umat manusia berdosa agar mereka mendapatkan kehidupan dan keselamatan walaupun nyawanya sendiri harus menjadi harga yang dibayar di kayu salib. Pengabdian diri merupakan bukti totalitas di dalam melayani Tuhan dan sesama. Maka, gembala yang kurang cakap dalam melaksanakan tugasnya, tidak memiliki hati sebagai pelayan, lebih memberi perhatian pada fasilitas dan materi finansial untuk kepentingan pribadinya sehingga jemaat dijadikan ladang pendapatan tanpa memberi perhatian pada kebutuhan 
pertumbahan mereka secara rohani (Despri \& Usat, 2020) Penghargaan yang bersifat kekal bagi gembala yang memimpin dengan memberi teladan.

1 Petrus 5:4 yang berbunyi "Dengan demikian, ketika nanti Sang Gembala Agung datang, kamu akan menerima mahkota kemuliaan yang tidak akan layu." memberi ilustrasi janji Tuhan yang menanti bagi para gembala yang setia melayani dengan memberi teladan bagi jemaat yang telah dipercayakan dalam bimbingan mereka oleh Tuhan. Sang Pemilik Tunggal domba-domba sendiri ketika datang kembali akan menilai dan memberi hadiah yang bukan dari dunia dan tidak fana. Segala kemuliaan yang dicari oleh gembalaan upahan yang didorong oleh hawa nafsu dan keserakaan hanya berlaku di dunia ini dan bersifat sementara. Mahkota berbicara prestige dan kemuliaan berbicara hadirat Allah yang kekal dimana para gembala setia yang memberi keteladanan akan menikmati hasil jerih payah pelayanan mereka dan hidup selamanya bersama Sang Gembala Agung.

\section{Kesimpulan}

Pertama, gembala sebagai pemimpin gereja perlu menyadari bahwa kepemimpinan-nya merupakan kepercayaan dan amanah dari Tuhan. Kedua, kualitas kepemimpinan gembala harus unggul dari kepemimpinan pada umumnya dengan memberi keteladanan melalui kesukarelaan dan pengabdian diri dalam melayani jemaat yang dipimpinnya. Ketiga, terdapat penghargaan yang bersifat kekal bagi gembala yang memimpin dengan memberi teladan.

\section{BIBLIOGRAFI}

Anggito, Albi, \& Setiawan, Johan. (2018). Metodologi penelitian kualitatif. CV Jejak (Jejak Publisher).

Baharun, Hasan. (2018). Peningkatan kompetensi guru melalui sistem kepemimpinan kepala madrasah. At-Tajdid: Jurnal Ilmu Tarbiyah, 6(1), 1-26.

Benjamin, Samuel Jebaraj, \& Biswas, Pallab. (2019). Board gender composition, dividend policy and COD: the implications of CEO duality. Accounting Research Journal.

Despri, Despri, \& Usat, Yahya. (2020). Peranan Gembala Sidang Dalam Pertumbuhan Iman Kaum Muda. Jurnal Teologi Praktika, 1(2), 81-90.

Dewi, Indah Kusuma. (2019). Nilai-nilai Profetik Dalam Kepemimpinan Modern Pada Manajemen Kinerja. Gre Publishing.

Hakh, Samuel Benyamin. (2019). Keteladanan dan Belarasa seorang Gembala sebagai Pemimpin yang Authentik.

Liliaprianty, Ruth. (2020). Gambaran Pola Konsumsi (Inhibitor, Enhancer Zat Besi), Aktivitas Fisik, Dan Asupan Zat Besi (Fe) Pada Remaja Putri Di Pulau Barrang Lompo Kota Makassar. Universitas Hasanuddin. 
Nurkarsa, Aldo Hermaya Aditia. (2019). Program Aplikasi Pengadaan Barang pada PT Kartu Perdana Berbasis Dekstop. Equivalent: Jurnal Ilmiah Sosial Teknologi, 1(1), $5-22$.

Purwanto, Agus. (2020). Kepemimpinan Yesus Kristus sebagai Model Kepemimpinan Kristen. Mathetes: Jurnal Teologi Dan Pendidikan Kristen, 1(2), 131-146.

Razak, Ahmad, Mokhtar, Mustafa Kamal, \& Sulaiman, Wan Sharazad Wan. (2018). Terapi Spiritual Islami: Suatu Model Penanggulangan Gangguan Depresi. Intuisi: Jurnal Psikologi Ilmiah, 6(2), 68-73.

Rupa, Calvin Sholla. (2016). Ciri Khas Seorang Gembala Berdasarkan Perspektif 1 Petrus 5: 1-4. Jurnal Jaffray, 14(2), 165-188.

Samarenna, Desti, \& Siahaan, Harls Evan R. (2019). Memahami Dan Menerapkan Prinsip Kepemimpinan Orang Muda Menurut 1 Timotius 4: 12 Bagi Mahasiswa Teologi. BIA': Jurnal Teologi Dan Pendidikan Kristen Kontekstual, 2(1), 1-13.

Sitepu, Elisabeth. (2019). Kepemimpinan Kristen Di Dalam Gereja. Jurnal Pendidikan Religius, 1(1), 7-11.

Tambunan, Bonifasius, Sihombing, Halomoan, Doloksaribu, Ardin, \& Muda, Iskandar. (2018). The effect of security transactions, easy of use, and the risk perceeption of interest online buying on the e-commerce tokopedia site (Study on Tokopedia. id site users in Medan city). IOP Conference Series: Materials Science and Engineering, 420(1), 12118.

Wibowo, Catur Hari. (2015). Problematika Profesi Guru dan Solusinya bagi Peningkatan Kualitas Pendidikan di MTs Negeri Nguntoronadi Kabupaten Wonogiri. Tesis tidak diterbitkan. Surakarta: Pascasarjana Institut Agama Islam Negeri

Wibowo, Udik Budi. (2011). Teori Kepemimpinan. Badan Kepegawaian Daerah Kota Yogyakarta [Skripsi].[Internet].[Diunduh 26 September 2017]. Tersedia Pada: Http://Staff. Uny. Ac. Id/Sites/Default/Files/Tmp/C, 20201113. 